\title{
El itinerario cultural como recurso turístico. Una propuesta transnacional
}

\author{
$M^{\mathrm{a}}$ Mercedes Fernández Martín \\ Dpto. Historia del Arte \\ Universidad de Sevilla
}

En los últimos años se ha experimentado un auge considerable del llamado turismo artístico o histórico artístico -mejor que cultural que implica una innumerable variedad de definiciones que quedan concretadas en otras tipologías de turismo- 1 . No obstante, hay que partir de la base de que los factores humanos, y especialmente los culturales, no son el principal tema de desplazamiento turístico. Sin embargo, el elemento cultural está siempre presente en cualquier tipo de viaje, ya sea como motivación destacada o como motivación complementaria.

El turismo de motivación histórico-patrimonial se desarrolla en el marco de un contexto artístico, ya sea urbanístico, arquitectónico, escultórico, pictórico, etc., pudiendo diferenciarse en turismo de motivación monumental, cuando el contexto histórico arquitectónico es un edifico emblemático y en turismo de exposiciones, cuando el contexto histórico artístico se contempla en un marco reducido. Este último es el característico de los museos, pinacotecas, bibliotecas y salas de exposiciones. En este sentido el museo es siempre un elemento de valor para el turista y, a pesar de centrarse, a priori, en el mismo tipo de contenido que algunos espacios monumentales, los museos son espacios cerrados. La visita a los museos ha sido siempre una práctica turística que se ha visto incrementada notablemente con la potencialización de acontecimientos singulares como la celebración de grandes exposiciones monográficas, que aumentan notablemente la asistencia a los museos ${ }^{2}$.

En los últimos años este tipo de turismo ha sido propiciado desde las instituciones públicas, tanto nacionales y autonómicas como provinciales y municipales, con la creación de los Patronatos de Turismo. Todas llevan a cabo una importante campaña de difusión sobre el rico patrimonio artístico de España, uno de los países europeos, junto a Italia y Grecia, donde el turismo basado en el disfrute del arte a través de sus monumentos, museos, galerías, exposiciones, yacimientos arqueológicos, centros históricos o conjuntos monumentales ha adquirido gran importancia en los últimos años, creándose nuevas alternativas. El objetivo es realizar un sistema que informe claramente al público usuario de elementos del patrimonio cultural acerca de la calidad de sus recursos.
Surgen así proyectos de colaboración como el propuesto entre la UNESCO, el Consejo de Europa y la Comisión Europea dentro del Plan de Acción Comunitario a favor del Turismo, destacando entre los objetivos el favorecer el intercambio de información y colaboración entre los diferentes sectores del turismo y la cultura. Se puede incluir también el Programa Cultura 2000 de la Unión Europea, al que puede acceder todo operador o agente cultural de cualquiera de los países participantes. Con ello se pretende también promover un mejor enfoque de la utilización del patrimonio cultural por los turistas y el intensificar la información de los agentes del turismo cultural. En el ámbito nacional puede servir de ejemplo el esfuerzo realizado para impulsar una de las rutas artísticas más antiguas, el Camino de Santiago. Para el año Jacobeo de 1993 se realizó un verdadero esfuerzo que dio sus frutos, reactivándose el turismo de interior en una amplia zona interregional, declarándose Primer Itinerario Cultural Europeo, perfectamente consolidado en la actualidad ${ }^{3}$.

En esta misma línea, con motivo de la celebración del Mundial de Esquí de Sierra Nevada (Granada), en el año 1995, se creó el proyecto turístico de El Legado Andalusí que, desgraciadamente, no ha tenido la repercusión esperada. La Junta de Andalucía hizo un llamamiento a la participación de todos para convertir este proyecto en un motor de generación de riqueza y difusor del importante patrimonio cultural y patrimonial del antiguo Al-Andalus. En este proyecto se implicó a más de 250 municipios en toda Andalucía y algunas provincias limítrofes, ampliándose la participación a otros países. En este sentido, El Legado Andalusí cumple también un papel político cuya misión es fomentar y mejorar las relaciones entre Europa y la ribera sur del Mediterráneo. Sirva de ejemplo una de las primeras rutas propuestas por El Legado, la de los Almorávides y Almohades para fomentar el conocimiento mutuo de los pueblos norteafricanos e ibero-

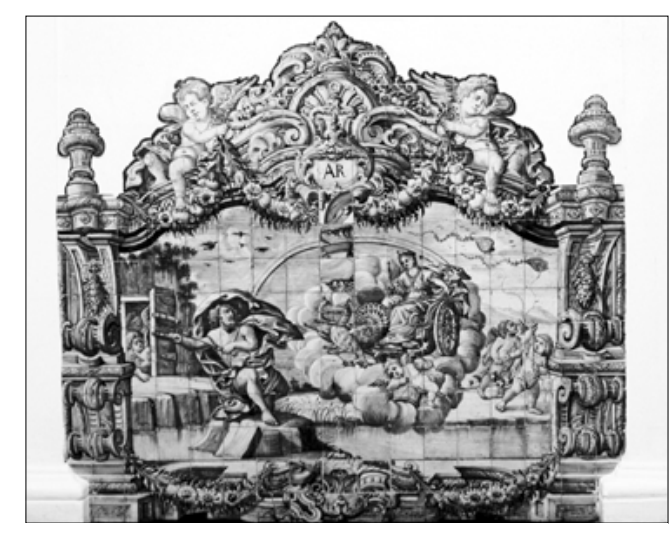

I. Evora. Universidad. Los cuatro elementos. Aire. Siglo XVIII. 


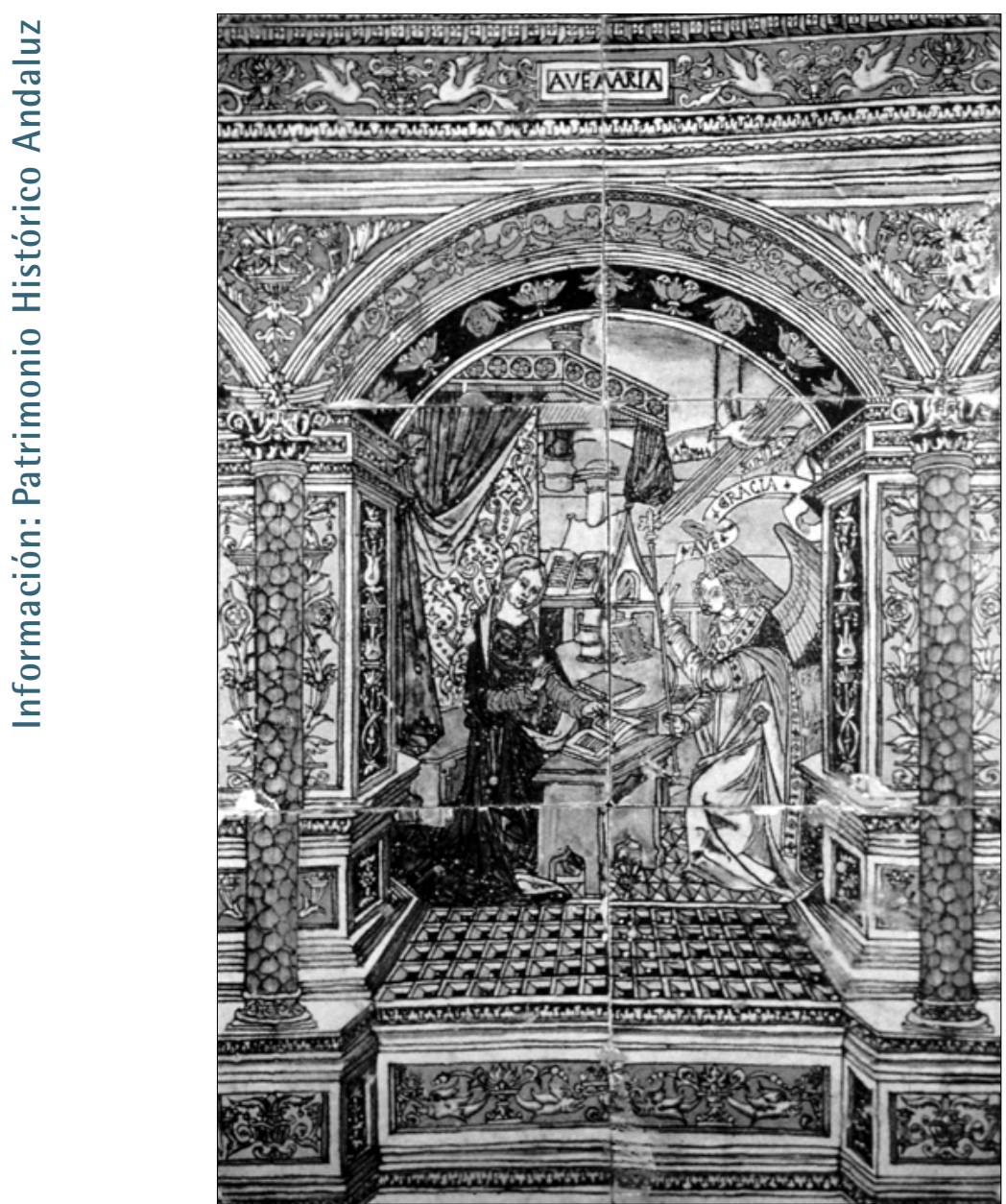

2. Evora. Anunciación. Ca. 1515 Francisco Niculoso Pisano.

americanos con el andaluz y que integra a España, Portugal, Marruecos, Argelia, Túnez, Mauritania, Malí y Senegal. Otras rutas propuestas en este proyecto son la recientemente señalizada que recorre la Campiña sevillana bajo el nombre de Ruta de Washington Irving que recorre veintitrés localidades de las provincias de Sevilla, Málaga y Granada que han firmado un convenio con la Consejería de Turismo y Deportes para la mejora de monumentos y conjuntos de interés cultural y turístico; o la no menos ambiciosa Ruta de Al-Mutamid, compuesta por dos subrutas en territorio portugués: una por el interior y otra por el Algarve, para posteriormente conectar con Sevilla y cuyos hitos principales serían Lisboa, Évora, Beja, Almonaster, Silves, Faro, Huelva, Niebla y Sevilla.

En la actualidad se pretende el desarrollo turístico de otra ruta de gran tradición, la Ruta de la Plata, que atraviesa de sur a norte el occidente peninsular. Para ello se ha creado la Red de Cooperación de Ciudades en la Ruta de la Plata, cuyo objetivo principal es impulsar uno de los más importantes y atractivos itinerarios de Europa. Pero éste se tiene que complementar con una mejora de los sistemas de comunicaciones y de las infraestructuras turísticas, en general. Los tres ejemplos citados, aunque existen otros de menor alcance territorial, implican el desarrollo turístico de varias comunidades autonómicas que a su vez divulgan el conocimiento de su patrimonio cultural. La poten- cialización de estos recursos es muy diversa y se puede articular tomando como referencia una corriente artística o varias, la obra de un autor, la vida de un artista, etc., estableciéndose rutas e itinerarios que, en la mayoría de los casos, pueden complementarse con otros recursos turísticos, caso de los naturales.

Como es sabido, el turismo se desarrolla en aquellos espacios que presentan una serie de recursos y atractivos que generan demanda turística. Sin embargo, hay que tener también presente que los factores que identifican la localización turística tienen como elemento de relativización el efecto de la moda y de las comunicaciones. Todo itinerario, circuito o ruta turística necesita, pues, de un ámbito geográfico donde desarrollarse. La ponderación de los recursos del territorio ofrecerá un punto de partida realista y ventajoso para el planteamiento de modelos de desarrollo y estrategias. En esta línea, aprovechando la importancia turística de Sevilla como producto cultural y la política de fomento turístico interprovincial de la Ruta de la Plata, se puede contemplar el desarrollo conjunto con el Alentejo portugués, que aporta a su vez un rico patrimonio cultural, localizado principalmente en el concejo de Évora. En este sentido el conocimiento de los recursos histórico-artísticos de la Ruta de la Plata tienen un complemento imprescindible en el país vecino. Durante mucho tiempo la historia y el arte peninsular tuvieron un desarrollo paralelo, aunque con sus propias peculiaridades nacionales, donde las influencias recíprocas fueron múltiples. Por otra parte, la nueva realidad europea hace que la frontera, antiguo escenario de disputas territoriales, se convierta hoy en lugar de encuentro de dos pueblos con voluntad de futuro. Uno de los mejores medios para llevar a cabo este proyecto común es el turismo, con un desarrollo conjunto se impulsa la creatividad y la difusión transnacional de la cultura y se pone en valor la diversidad cultural y el patrimonio común ${ }^{4}$.

No es nuestro propósito enumerar o describir el rico patrimonio de esta amplia zona que abarca las provincias de Sevilla y Badajoz y el concejo de Évora. Se trata sólo de resaltar aspectos concretos por potenciar dentro de la misma, destacando entre ellos los bienes muebles que, en muchas ocasiones, han pasado desapercibidos si no se encontraban englobados en colecciones museográficas o en conjuntos arquitectónicos importantes. Sin ánimo de "crear" un itinerario turístico sino simplemente hacer unas reflexiones sobre la permeabilidad fronteriza, aprovechando precisamente el desarrollo turístico de la Ruta de la Plata, se puede plantear una ruta artística de gran interés en torno a la obra del ceramista Francisco Niculoso Pisano, introductor de una nueva técnica y un nuevo lenguaje decorativo en la Península Ibérica. Sirva de ejemplo la decoración cerámica y, en concreto, la de los retablos cerámicos que este artista dejó en esta zona, máxime cuando el desarrollo de la cerámica española y portuguesa corre paralelo en los primeros años de su desarrollo.

La decoración de ladrillo vidriado en la arquitectura ha tenido y tiene un amplio desarrollo en la Península 
Ibérica. En Portugal las influencias de tipo mudéjar procedentes de maestros ceramistas españoles marcaron los inicios del azulejo en ese país a mediados del siglo XV, con la compra de azulejos de cuerda seca y arista a los alfares sevillanos. No obstante, es durante el siglo XVI cuando, gracias a nuevas corrientes artísticas que procedían de Italia, se produce un auténtico auge de la utilización del azulejo como ornamento esencial de edificios públicos y privados. Lo clásico y lo exótico, los gustos italianos, flamencos e incluso la huella americana, todo se mezcla dando estilos diferentes. También va a ser en ese siglo cuando la azulejería portuguesa inicie su propio camino y desarrollo que no se ha visto frenado desde entonces, convirtiéndose en un elemento decorativo característico y "nacional" de la arquitectura de Portugal de todos los tiempos.

Desde 1479 está documentada la exportación de azulejos sevillanos a territorio portugués. En ese año el taller trianero de Fernando Martínez Guijarro enviaba al país vecino un cargamento de azulejos de los que no se menciona a dónde iban destinados. Es el documento más antiguo sobre este comercio pero hay que tener en cuenta que no fue el único y, la procedencia de los azulejos también fue variada, sirva de ejemplo la cerámica de Manises utilizada en la pavimentación de varios edificios portugueses. En unos y otros la temática es de clara influencia mudéjar. En los motivos decorativos destacan los que imitan las labores de tejidos, medallones circulares y estrellados, madejas, etc., conocidos en la época con el nombre de "azulejos de labores", formándose el dibujo a veces cada cuatro losetas, y donde se alterna la técnica de cuerda seca y arista, al igual que ocurría en España. A lo largo del siglo XVI la cerámica de gusto mudéjar siguió teniendo bastante desarrollo pero ya desde los primeros años de la centuria es progresivamente sustituida por la introducción de la técnica de la majólica y la importación de productos y, sobre todo, la presencia de artífices italianos y flamencos 5 .

Sevilla fue durante el siglo XVI la principal fuente de encargos cerámicos hechos para Portugal, siendo curioso destacar que no se limitó al repertorio tradicional sevillano sino que también trabajó con diseños enviados desde Lisboa. Sirva de ejemplo el conjunto de azulejos que decoran buena parte del palacio de Sintra, donde el único motivo es la esfera armilar, emblema de Manuel I, impulsor de las reformas efectuadas en el palacio en los primeros años del siglo XVI6. Se trata de azulejos sevillanos exclusivos para el palacio, realizados al margen de la producción habitual.

El destino de los azulejos sevillanos no fue únicamente Sintra sino otros edificios protegidos por el mismo don Manuel. El convento de la Concepción de Beja conserva en la Sala del Capítulo una decoración de azulejos de arista procedentes de Sevilla y que recuerdan en su organización a los paneles que decoran algunas estancias de la sevillana Casa de Pilatos. En este mismo sentido los encargos llegaron hasta Coimbra, utilizándose en el revestimiento de los pilares de la Catedral Vieja, donde los azulejos forman

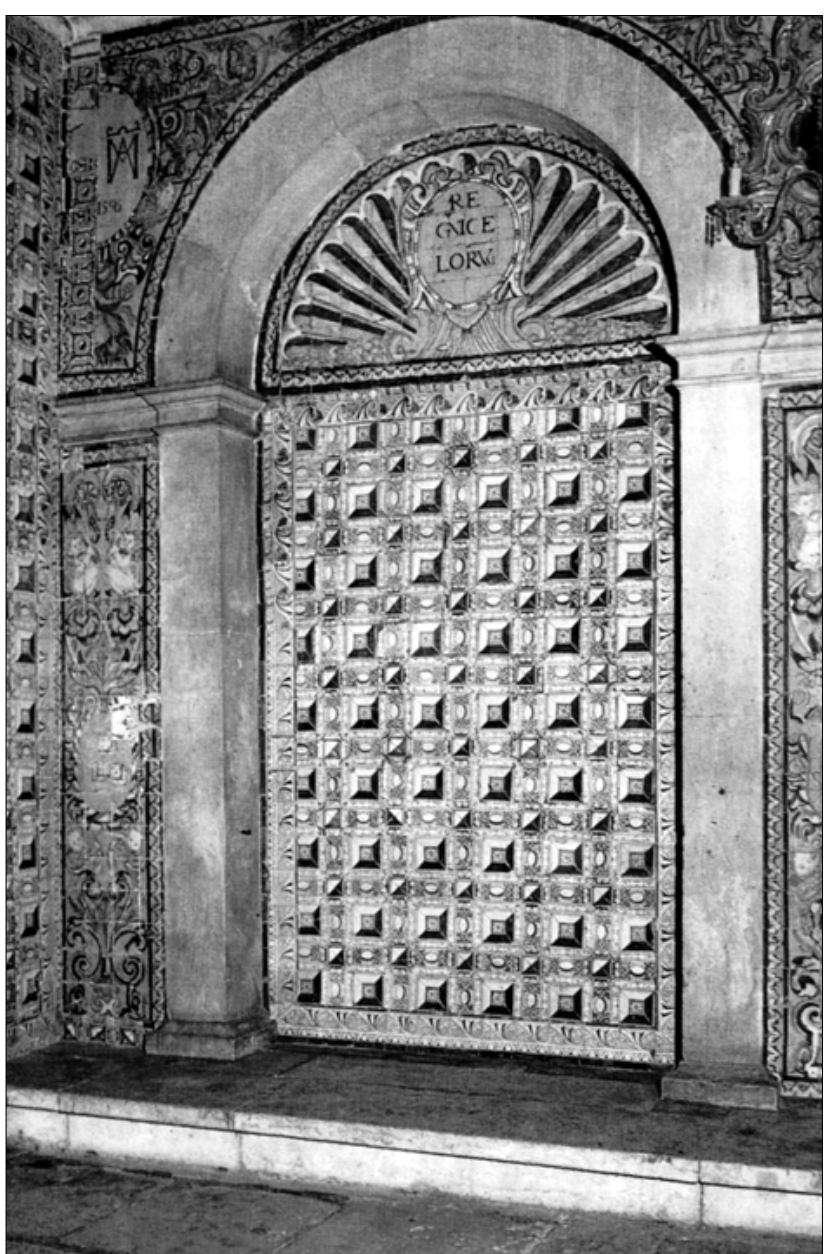

composiciones arquitectónicas características de Por3. Lisboa. Iglesia de San Roque. 1596 bién en la quinta de Bacalhoa, en Azeitâo, donde se utiliza azulejo de arista sevillano, siendo la última importación de Sevilla que se recoge, intercalándose con otra producida en Lisboa, ya en la nueva técnica de la majólica italiana. A pesar de esta sumisión a los repertorios decorativos impuestos por los talleres sevillanos y a la importancia de crear un gusto con importantes repercusiones en la producción nacional, esta decoración va a tener cierta originalidad en territorio portugués al darse desde siempre algunas soluciones originales. Estas se aprecian sobre todo en la disposición de los azulejos, independizándose a partir de la introducción de la nueva técnica de superficie lisa y cuando ésta empieza a producirse en tierras portuguesas. Al contrario que en España, donde las paredes eran casi siempre revestidas por un único motivo, cerrado por enmarques, en Portugal los azulejos sevillanos se usaron combinando varios tipos de motivos y enmarques. Como afirma Meco, de esta combinación resultaron esquemas complejos, llenos de sugestiones arquitectónicas y de efectos dinámicos, que será lo que caracterice la azulejería portuguesa posterior. Debe destacarse esta utilización original, tratándose de un material importado 7 .

A finales del siglo $X V$ y principios del $X V I$, los talleres peninsulares comienzan a recibir artistas flamencos e 

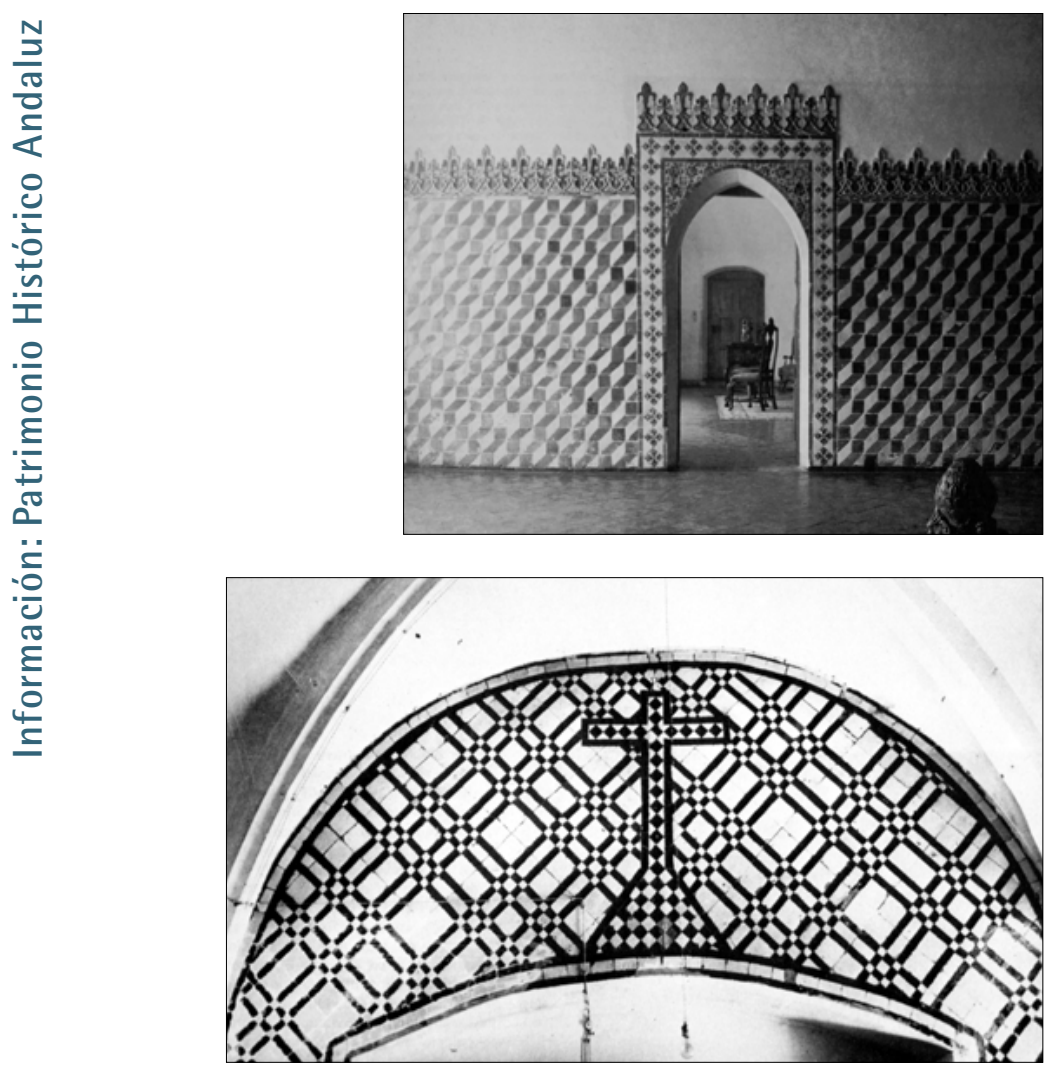

4. Sintra. Palacio Real. Ca. 1500

5. Evora. Ermita de San Blas. 1575. italianos que van a divulgar la nueva técnica que permitía pintar a pincel sobre la placa de azulejo cocido, para posteriormente someterla a un esmaltado transparente. Pero estos artistas no sólo van a introducir una nueva técnica, sino que con ellos entra también una renovación estilística. El que mejor representa esta introducción en la Península lbérica es Francisco Niculoso, probablemente natural de Pisa y documentado en Sevilla desde los últimos años del siglo $\mathrm{XV}$, a quien también se le hicieron encargos en otras regiones españolas y en tierras portuguesas, dado el prestigio y fama que alcanzó con la nueva técnica de la cerámica de superficie lisa. La vida y la obra de Francisco Niculoso Pisano, como siempre fue conocido, está ampliamente estudiada y aquí nos vamos a ceñir exclusivamente a articular un itinerario en torno a su obra en el ámbito geográfico propuesto ${ }^{8}$. Para ello hay que empezar por Sevilla, ciudad donde se encuentra el mayor número de obras documentadas del artista, aunque éstas fueron escasas, y donde se estableció y residió hasta su muerte, acaecida posiblemente en los primeros meses de 1529, trabajando para las clases sociales más altas, las únicas que podían apreciar y pagar la novedad que representaba la nueva técnica?

El itinerario parte desde Triana, donde se encuentra la primera obra documentada de Niculoso Pisano, en concreto en la iglesia de Santa Ana. En el muro de la nave de la epístola se encuentra una lauda sepulcral que pertenece, según la inscripción que la rodea, a Îñgo López, fechándose en I503. Es una obra en la que todavía se evidencian elementos de origen gótico, pero donde se advierte un perfecto dominio del dibujo, con un trazo preciso, aunque falta el sentido del volu- men. Es muy significativo este primer encargo para la iglesia de Santa Ana, ya que es en este arrabal sevillano donde estaban establecidos los principales talleres alfareros y por tanto a donde debió dirigir sus primeros pasos el recién llegado, instalando su taller en la calle Pureza. Desde el punto de vista turístico, el recorrido se puede complementar con la visita a un taller cerámico, de los muchos que existen todavía en el barrio, donde se puedan estudiar e identificar las diferentes técnicas empleadas en la azulejería y su evolución a lo largo de los siglos.

Como ya se ha señalado, es en Sevilla donde más obras documentadas se conservan del maestro ceramista. Su participación en la portada de la iglesia del monasterio jerónimo de Santa Paula le debió dar la fama y el reconocimiento de una clientela culta que sería, a partir de estas fechas, la gran demandante de su producción. Aparte de los valores arquitectónicos que presenta, dentro de la arquitectura gótica del período de los Reyes Católicos, lo más sobresaliente es su decoración cerámica con tondos y grutescos a la manera italiana. La obra aparece fechada en 1504 y en ella intervino también el escultor Pedro Millán, encargado de las esculturas que albergan los tondos, aunque la central suele atribuirse al taller de Andrea Della Robbia. La decoración cerámica es obra de Niculoso Pisano y es donde por primera vez se utilizan en Sevilla temas de grutescos. El repertorio de los mismos es escaso, pero articulando los motivos con gran habilidad, evitándose la monotonía.

Para este mismo monasterio y para la puerta del compás realizó Niculoso Pisano un panel que representaba a Santa Paula, la titular del mismo. La obra fue descrita por Gestoso, quien todavía conoció el panel. La santa aparecía de pie recortada en un fondo de paisaje encuadrado por una estructura arquitectónica adornada con motivos de trofeos ${ }^{10}$. En la parte inferior figuraban los escudos de España y de Portugal junto al de la mecenas doña Isabel Enríquez, marquesa de Montemayor, conocida popularmente como marquesa de Portugal, al ser la esposa del Condestable de Portugal.

De las mismas fechas es el otro gran encargo que recibió Pisano en Sevilla: la ejecución de dos retablos de azulejos para el Alcázar sevillano, encargados por los Reyes Católicos para sus dependencias privadas, de los que sólo se conserva uno de ellos. El desaparecido se conoce a través de algunas descripciones como las de Ceán Bermúdez y Arana de Varflora 'I. Representaba la Santísima Trinidad y la Coronación de la Virgen con el típico repertorio decorativo de grutescos, lauras, cartelas y roleos vegetales. Sí se conserva en el pequeño oratorio de los Reyes Católicos el dedicado a la Visitación de la Virgen por su prima Santa Isabel, tema que se complementa con la representación de la Anunciación y la Genealogía temporal de Cristo, conforme a la imagen del árbol de Jesé. Estos temas narrativos van acompañados de una rica decoración de grutescos, candelabros y frisos, donde alterna un rico repertorio ornamental de animales, mascarones, cuernos de la abundancia, jarrones, cartelas, "puttis", bu- 
cráneos, aves, etc. que se complementan con cintas y roleos y el lema de los Reyes Católicos representado por el yugo y las flechas con el Tanto Monta.

Toda esta decoración es de claro sabor renacentista, inspirado directamente en los modelos italianos, mientras que los motivos principales se inspiran en grabados de procedencia centro europea y de claro carácter goticista, dándose un marcado contraste entre unos y otros. El programa iconográfico propuesto parece hacer alusión a la Redención, habiéndose elegido como tema principal el de la Visitación por su alusión al nombre de la reina que había encargado el retablo 12

Gran importancia tiene otra de las obras ejecutadas por Niculoso Pisano, dentro del marco geográfico que nos ocupa: el altar mayor de la iglesia de Santa María de Tentudía, situada en el término municipal de la población pacense de Calera de León, en la raya fronteriza con Portugal, a escasos kilómetros de Monesterio, en plena Ruta de la Plata. El retablo fue contratado en 1518 para conmemorar la victoria sobre los musulmanes de Pelay Pérez Correa, maestre de la Orden de Santiago, según la leyenda con la intervención de la Virgen, que detuvo el día el tiempo necesario para que se produjera la victoria. En la población se encuentra el convento de los caballeros de la Orden de Santiago con su iglesia gótica y el claustro del siglo XVI.

A pocos kilómetros de la población y sobre una elevación se encuentra la ermita donde la tradición sitúa la batalla en la que se detuvo milagrosamente el día. Ésta, de pequeñas dimensiones, alberga el retablo mayor dedicado a la Vida de la Virgen, una de las obras más interesantes firmadas de Niculoso Pisano. Al estar destinado a presidir un espacio mayor está configurado como un auténtico retablo, siguiendo los esquemas de la época, organizándose en tres calles, con las laterales divididas en tres cuerpos. El espacio central está presidido por una gran hornacina, donde se simula un dosel, dispuesta para albergar una imagen mariana, rodeada por el Árbol de Jesé, tema utilizado con anterioridad en el retablo del Alcázar sevillano. En las calles laterales se disponen las diferentes escenas, situándose a los pies las figuras del fundador y del promotor de la obra, respectivamente. De izquierda a derecha y de abajo arriba aparecen el Nacimiento, la Anunciación, la Asunción-Coronación y la Presentación-Purificación. El conjunto del retablo se remata con el tema del Calvario. Las escenas están rodeadas por la típica decoración de grutescos utilizada en otras obras del maestro y que aquí se complementan con temas heráldicos alusivos a la Orden de Santiago. Los retablos laterales de esta iglesia son también cerámicos pero se pueden fechar unos años más tarde, aunque su procedencia sea también sevillana. Coetáneos a la producción de Niculoso son los azulejos que decoran las paredes del presbiterio, las gradas del altar mayor y la mesa de altar, atribuidos por Frothingham al ceramista trianero Fernán Martínez Guijarro 13.

Esta participación de Martínez Guijarro con Francisco Niculoso puede explicar la existencia en Portugal de obras ejecutadas por el maestro italiano. Ya se ha co-
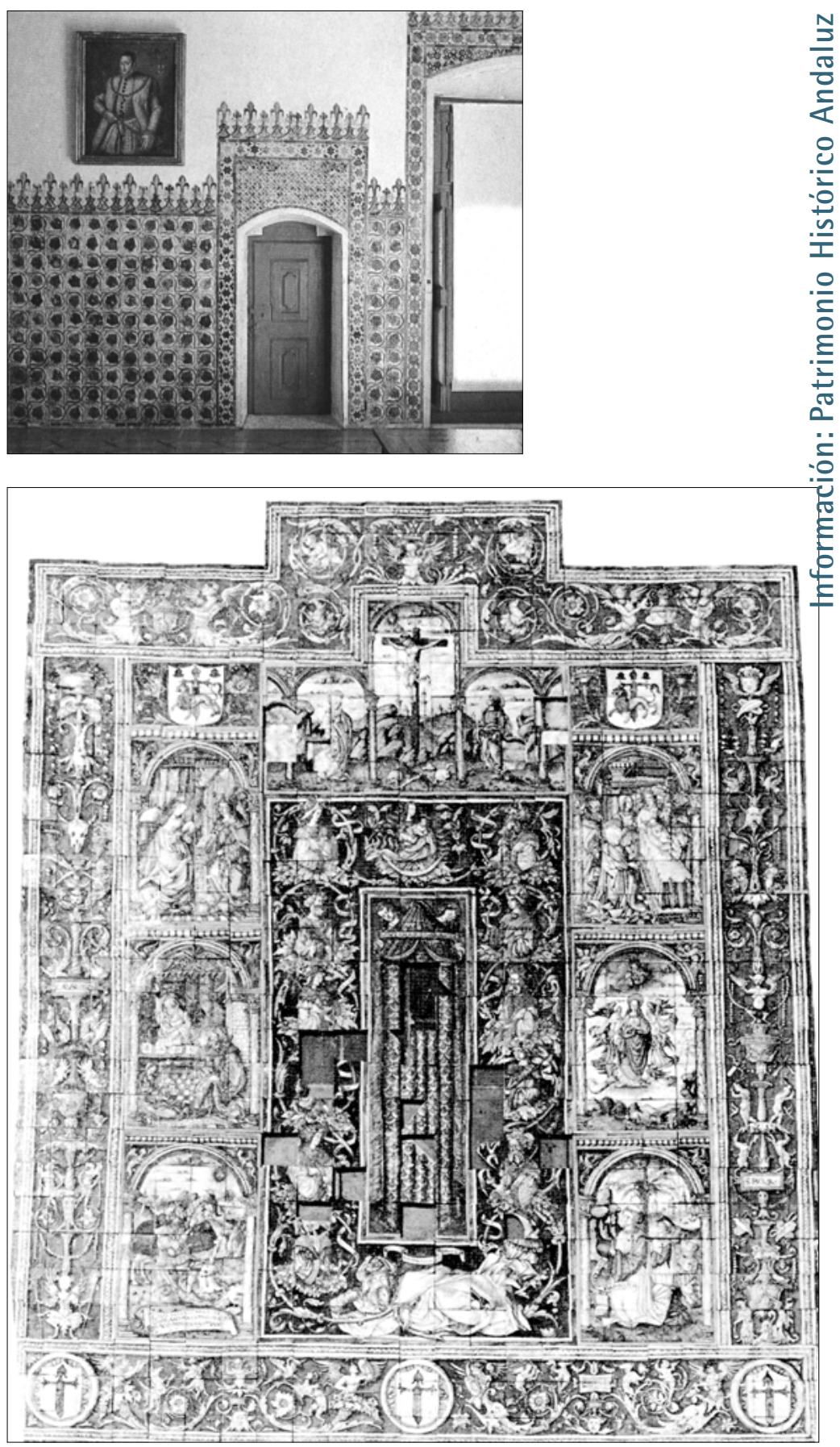

6. Quinta de Bacalhoa. _ siglo XVI.

mentado cómo el taller de Martínez Guijarro exportó con bastante asiduidad azulejos para la decoración de varios edificios, entre los que cabe destacar el palacio real de Sintra y la catedral vieja de Coimbra. Está documentada la presencia en Portugal de un panel de azulejos con el tema de la Visitación firmado por $\mathrm{Ni}$ culoso Italiano pero no fechado. Este fue localizado en | 882 en la colección del rey Fernando || de Portugal, pasando en 1902 a formar parte de los fondos del Rijskmuseum de Amsterdam ${ }^{14}$. Este importante panel es la primera obra, conocida en Lisboa, de azulejo renacentista.

Pero el itinerario en torno al ceramista Francisco Niculoso continúa en tierras de Portugal, en concreto
7. Badajoz. Calera de León. Francisco Niculoso Pisano. Retablo del Monasterio de Tentudia. 1518. 


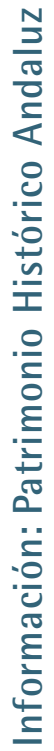
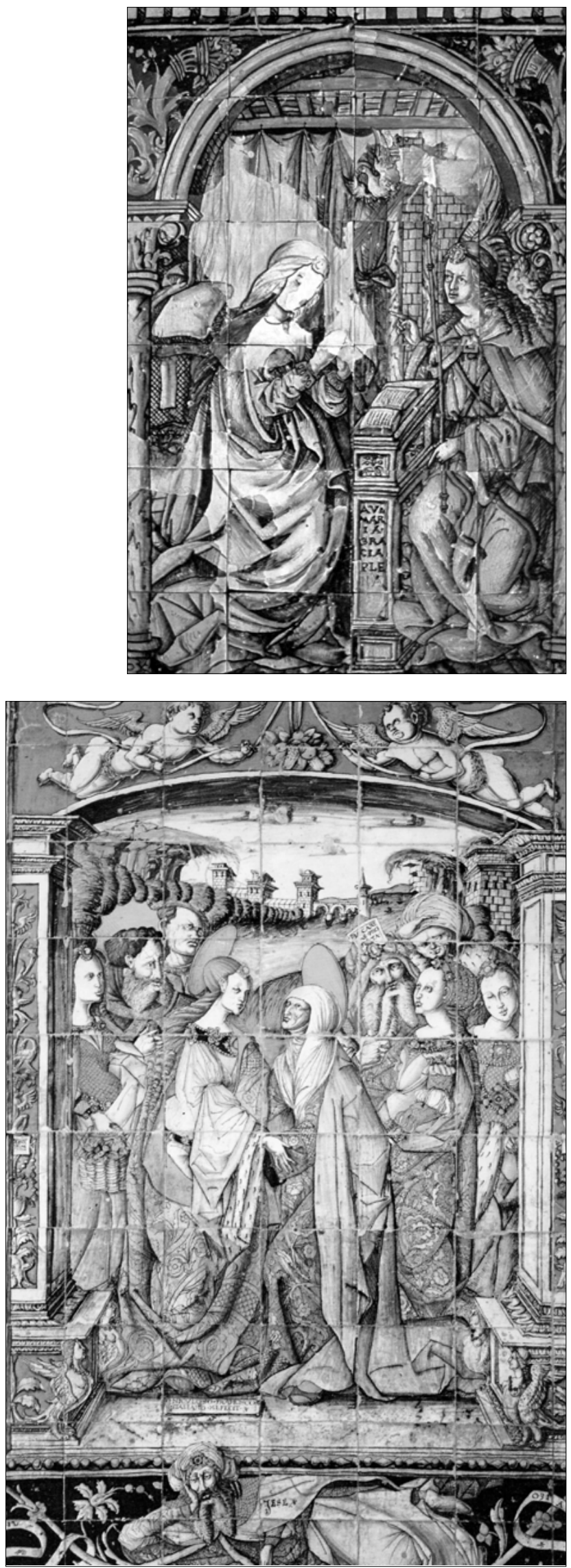

Al igual que ocurrió en España, en Portugal la primera corriente italianizante coincidió con la primera mitad del siglo y se introdujo por vía sevillana a través de los diseños de Francisco Niculoso. Su obra marcó la pauta de los demás artistas ceramistas y divulgó, junto con la técnica, la utilización de los temas de grutescos. A partir de la década de los treinta, una vez muerto el maestro, el taller no supo continuar el gran avance que había supuesto su obra, volviéndose de nuevo a la técnica de cuenca o arista. A pesar de ello, los motivos renacentistas se mantendrían, aunque a menor escala. La definitiva renovación llegaría mediado el siglo XVI, concretamente en la década de los sesenta. Es a partir de esas fechas cuando en España y Portugal se produce una renovación del azulejo, pero en esta ocasión es por conductos flamencos y por el establecimiento de nuevos maestros italianos en territorio peninsular. No obstante, Portugal, durante algunos años, va a seguir abasteciéndose en los talleres sevillanos y, a lo más, de los de Talavera de la Reina, revitalizados a partir de la influencia flamenca y que empezarían a jugar un papel muy importante en el comercio peninsular. Esta importancia de la azulejería en Portugal propició su total independencia a partir de los primeros años del siglo XVII, dominada a partir de esos años por la influencia flamenca.

Aunque existen otras obras, firmadas o atribuidas, del maestro ceramista aquí nos hemos limitado a enumerar las obras localizadas en un sector con un potencial turístico reconocido. Su difusión integrada dentro de un itinerario como el propuesto sirve de aprovechamiento y conocimiento de una amplia región de incalculable valor patrimonial, a la que se suman reconocidos recursos naturales que incrementan su interés. Es importante señalar por tanto que en esta propuesta se combinan espacios urbanos de gran dinamismo, Tentudia. Detalle. $15 / 8$.

9. Sevilla. Alcázar. Retablo de la Visitación. Francisco Niculoso Pisano. Sevilla, I504. como Sevilla y Évora, ciudad esta última declarada Pa- 
trimonio de la Humanidad, con espacios rurales y poblaciones pequeñas. La presencia de monumentos y museos, con otros aspectos de dimensión cultural o geográfica más amplia, dotan a estos ámbitos de una proyección que se mide en el alcance de su difusión. Conocer la posible aportación del patrimonio como otro recurso del territorio es, además, una responsa- bilidad que deben asumir las políticas culturales y las de planificación territorial, orientadas a su preservación en el contexto del desarrollo sostenible. Pero hay que recordar que cualquier propuesta no es únicamente la elaboración del plan, sino sobre todo la gestión y desarrollo del mismo.

\section{Notas}

l. Turismo cultural, en un sentido amplio, es el conjunto de actividades que se desarrollan para facilitar unos conocimientos con el fin de ampliar la cultura desde una perspectiva del tiempo libre y de la civilización del ocio. Este englobaría desde el contacto con las distintas épocas históricas y artísticas, a través de la visita a conjuntos monumentales y museos, a las manifestaciones culturales y de espectáculos a través de festivales de música, teatro, cine, exposiciones, manifestaciones folclóricas, gastronómicas y de artesanía, sin olvidar la asistencia a cursos, seminarios, cursos de idiomas en el extranjero o a las Universidades de verano.

2. Sirva de ejemplo la afluencia de visitantes que recibió el Centro Andaluz de Arte Contemporáneo con motivo de la exposición "Velázquez y Sevilla", celebrada entre octubre y diciembre de 1999

3. Téngase en cuenta que esta Ruta atraviesa gran parte de la comunidad de Castilla-León que concentra casi la mitad del patrimonio monumental y artístico de España. Esta comunidad ha sabido potenciar su patrimonio con una serie de exposiciones, bajo el nombre de Las Edades del Hombre, que está dando a conocer el rico patrimonio religioso de esa comunidad.

4. En general, las relaciones económicas entre Andalucía y Portugal se intensificaron cuando los dos países entraron a formar parte de la Unión Europea, existiendo actualmente vínculos empresariales, concretamente turísticos, en el Algarve, que en la actualidad se pretende ampliarlos hacia el Alentejo.

5. PLEGUEZUELO HERNÁNDEZ, Alfonso: Azulejo seviIlano. Sevilla, 1989.

6. En 1508 el encargado de las obras que se estaban ejecutando en el palacio de Sintra anotaba la llegada al puerto de Belém de un cargamento de azulejos procedentes de Sevilla. Para el estudio del azulejo sevillano en Portugal véase, entre otros, MECO, José: Azulejos de Lisboa. Catálogo Exposición. Lisboa, 1984. Págs. 27-33.
7. MECO, José: Azulejaria Portuguesa. Lisboa, 1985.

8. Para el estudio exhaustivo sobre la vida y la obra del artista véase MORALES, Alfredo J.: Francisco Niculoso Pisano. Sevilla, 1977.

9. Los principales encargos fueron hechos por parte del arzobispado, la Catedral, Isabel Enríquez, marquesa de Montemayor, el Duque de Medina Sidonia, para los Condes del Real en Valencia y por los propios reyes.

10. GESTOSO Y PÉREZ, José: Historia de los barros vidriados sevillanos. Sevilla, 1904. Pág. 203.

I I. MORALES, Alfredo J.: "Francisco Niculoso Pisano y los azulejos sevillanos del siglo XVI". En Actas del I Congreso de Historia de Andalucía. Andalucía Moderna. Tomo II. 1978. Pág.224.

\section{MORALES: Ob. Cit. Págs. 50-52.}

13. FROTHINGHAM, Alice Wilson: Tile altars by Niculos Pisano and others at Tentudis, Spain. New York, 1969. Págs 29 y ss.

|4. Rijksmuseum, Amsterdam, inv. n PKR || 727.

15. Entre ellas cabe citar el apostolado realizado para la Cartuja de Santa María de las Cuevas, del que sólo se conservan dos paneles in situ, o los símbolos de los Tetramorfos del Museo de Bellas Artes de Sevilla. 